https://doi.org/10.36930/40310517

Article received 16.11.2021 p.

Article accepted 25.11.2021 p.

UDC 004.422:536.24
$@ \bowtie$ Correspondence author

V. I. Havrysh

vasyl.i.gavrysh@Ipnu.ua

\title{
АНАЛІЗ ТЕМПЕРАТУРНИХ РЕЖИМІВ У ТЕРМОЧУТЛИВИХ ШАРУВАТИХ ЕЛЕМЕНТАХ ЦИФРОВИХ ПРИСТРОЇВ, СПРИЧИНЕНИХ ВНУТРІШНІМ НАГРІВАННЯМ
}

Розроблено нелінійну математичну модель для визначення температурного поля, а в подальшому і аналізу температурних режимів у термочутливій ізотропній багатошаровій пластині, яка піддається внутрішнім тепловим навантаженням. Для цього коефіцієнт теплопровідності для шаруватої системи описано єдиним цілим за допомогою асиметричних одиничних функцій, що дає змогу розглядати крайову задачу теплопровідності з одним неоднорідним нелінійним звичайним диференціальним рівнянням теплопровідності з розривними коефіцієнтами та нелінійними крайовими умовами на межових поверхнях пластини. Введено лінеаризуючу функцію, за допомогою якої лінеаризовано вихідне нелінійне рівняння теплопровідності та нелінійні крайові умови і внаслідок отримано неоднорідне звичайне диференціальне рівняння другого порядку зі сталими коефіцієнтами відносно лінеаризуючої функції з лінійними крайовими умовами. Для розв'язування отриманої крайової задачі використано метод варіації сталих і отримано аналітичний розв'язок, який визначає запроваджену лінеаризуючу функцію. Розглянуто двошарову термочутливу пластину і, як приклад, вибрано лінійну залежність коефіцієнта теплопровідності від температури, яку часто використовують у багатьох практичних задачах. Внаслідок цього отримано аналітичні співвідношення у вигляді квадратних рівнянь для визначення розподілу температури у шарах пластини та на їх поверхні спряження. Отримано числові значення температури з певною точністю для заданих значень товщини пластини та ії шарів, просторових координат, питомої потужності внутрішніх джерел тепла, опорного та температурного коефіцієнтів теплопровідності конструкційних матеріалів пластини. Матеріалом шарів пластини виступають кремній та германій. Для визначення числових значень температури в наведеній конструкції, а також аналізу теплообмінних процесів в середині шаруватої пластини, зумовлених внутрішніми тепловими навантаженнями, розроблено програмні засоби, із використанням яких виконано геометричне зображення розподілу температури залежно від просторових координат. Отримані числові значення температури свідчать про відповідність розробленої математичної моделі аналізу теплообмінних процесів у термочутливій шаруватій пластині з внутрішнім нагріванням, реальному фізичному процесу. Програмні засоби також дають змогу аналізувати такого роду середовища, які піддаються внутрішнім тепловим навантаженням, щодо їх термостійкості. Як наслідок, стає можливим iї підвищити і захистити від перегрівання, яке може спричинити руйнування не тільки окремих елементів, а й всієї конструкції.

Ключові слова: температурне поле; ізотропна термочутлива пластина; теплопровідність; теплоізольована поверхня; ідеальний тепловий контакт; внутрішнє нагрівання.

\section{Вступ / Introduction}

Сучасне суспільство характеризується високим рівнем використання електронних пристроїв сучасної техніки для різноманітних потреб. Їх експлуатують у певних температурних режимах, що приводять до необхідності забезпечення надійної роботи, зменшення ваги i габаритів (мініатюризації), збільшення терміну служби. Внаслідок мініатюризації пристроїв та їх елементів у невеликих об'ємах концентруються високі потужності тепловиділення. Причому, при експлуатації мікроелектронні пристрої піддаються впливу як внутрішніх теплових потоків, так і зовнішніх. Тому залишається актуальною задача визначення температурних полів та аналізу температурних режимів у окремих елементах та вузлах електронних пристроїв, оскільки саме темпера- тура $є$ вагомим фактором, який значно впливає на їх ефективну роботу. На діаграмі (рис. 1) наведено вплив різних зовнішніх чинників на надійність роботи мікроелектронних пристроїв.

Численні дослідження [18, 21, 22, 23] свідчать про те, що кількість відмов при експлуатації мікроелектронних пристроїв тісно пов'язана з рівнем їхньої температури. Так, для германієвих елементів кількість відмов для температури $140{ }^{\circ} \mathrm{C}$ у 7,5 разів є більшою, ніж для температури $20^{\circ} \mathrm{C}$. Ще більшою є ця кількість відмов для кремнієвих елементів. Температурний рівень у елементах мікроелектронних пристроях може зростати за рахунок підвищення температури довкілля, нагрівання від сусідніх елементів, які виділяють тепло, теплової потужності самих елементів та пристроїв.

\section{Інформація про авторів:}

Гавриш Василь Іванович, д-р техн. наук, професор, кафедра програмного забезпечення. Email: vasyl.i.gavrysh@Ipnu.ua; https://orcid.org/0000-0003-3092-2279

Грицюк Юрій Іванович, д-р техн. наук, професор кафедри програмного забезпечення. Email: yurii.i.hrytsiuk@lpnu.ua; https://orcid.org/0000-0001-8183-3466

Цитування за ДСТУ: Гавриш В. І., Грицюк Ю. І. Аналіз температурних режимів у термочутливих шаруватих елементах цифрових пристроїв, спричинених внутрішнім нагріванням. Науковий вісник НЛтУ України. 2021, т. 31, № 5. С. 108-112.

Citation APA: Havrysh, V. I., \& Hrytsiuk, Yu. I. (2021). Analysis of temperature regimes in heat-sensitive layered elements of digital devices caused by internal heating. Scientific Bulletin of UNFU, 31(5), 108-112. https://doi.org/10.36930/40310518 


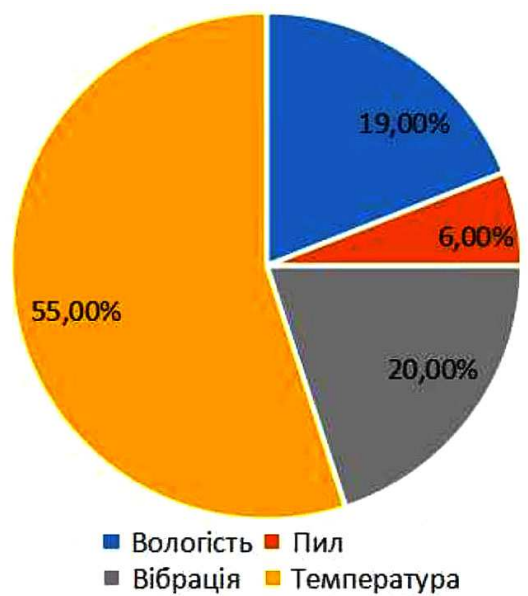

Рис. 1. Вплив різних зовнішніх чинників на надійність роботи мікроелектронних пристроїв / Influence of various external factors on the reliability of microelectronic devices

Тому моделювання процесів поширення тепла у різних конструкціях та їх елементах $є$ важливим напрямом теоретичних і практичних досліджень. Відомо, що елементи сучасних електронних пристроїв піддаються впливу внутрішнього нагрівання внаслідок їх експлуатації. Саме тому задачі математичного моделювання процесів, пов'язаних із теплоперенесенням, не втрачають актуальності й зараз, адже аналіз розв'язків таких задач має велике наукове, практичне, а також і економічне значення.

Експериментальні дослідження полів температури у різних конструкціях i, зокрема, у мікроелектронних пристроях не завжди дають можливість отримати необхідні результати для аналізу теплової поведінки пристрою. Варто зазначити також, що у багатьох випадках такі експерименти $є$ просто неможливими. Тому математичне моделювання процесів, пов'язаних із теплообміном, залишається важливим напрямом наукових досліджень. Вагомим аспектом моделювання та аналізу процесу теплопровідності у елементах конструкцій i, зокрема, мікроелектронних пристроїв, $\epsilon$ врахування впливу внутрішніх джерел тепла.

Отже, проблема розроблення нових математичних моделей як для однорідних середовищ, так і неоднорідних, а також удосконалення уже розроблених математичних моделей для аналізу процесу теплопровідності та теплообміну і надалі залишається актуальною.

Об'єкт дослідження - нелінійний процес теплопровідності в термочутливих середовищах із внутрішнім нагріванням.

Предмет дослідження - нелінійні математичні моделі процесу теплопровідності та методи визначення аналітичних розв'язків відповідних крайових задач для термочутливих середовищ із внутрішнім нагріванням.

Мета роботи - розроблення нелінійної математичної моделі теплопровідності для шаруватої пластини, що нагрівається внутрішніми джерелами тепла, яка дасть змогу підвищити точність визначення температурного поля, що у подальшому вплине на ефективність методів проектування мікроелектронних пристроїв цифрових технологій.

Для досягнення зазначеної мети визначено такі основні завдання дослідження:

- проаналізувати основні літературні джерела у напрямі розроблення нелінійних математичних моделей теплопровідності;
- навести об'єкт дослідження та його нелінійну математичну модель;

- навести спосіб лінеаризації цієї моделі;

- отримати аналітичний розв'язок нелінійної крайової задачі теплопровідності;

- розробити алгоритм і програмні засоби його числової реалізації для аналізу температурних режимів у термочутливій шаруватій пластині.

Наукова новизна отриманих результатів дослідження - наведено спосіб лінеаризації нелінійної математичної моделі теплопровідності, які отримано в замкнутому вигляді аналітичного розв'язку відповідної нелінійної крайової задачі для термочутливих середовищ із внутрішнім нагріванням.

Практична значущість результатів дослідження отриманий аналітичний розв'язок нелінійної крайової задачі теплопровідності для термочутливого середовища 3 внутрішнім нагріванням дає змогу розробляти алгоритми та програмні засоби його числової реалізації для аналізу температурних режимів у окремих конструкційних елементах та вузлах цифрових пристроїв, що дало змогу здійснювати прогнозування їхніх режимів роботи, ідентифікування невідомих параметрів i підвищення термостійкості, що збільшує термін їх експлуатації.

Аналіз останніх досліджень та публікацій. Визначення температурних режимів як в однорідних, так і в неоднорідних конструкціях привертає увагу багатьох дослідників [2, 18, 19, 21, 22, 23].

У роботі [3] наведено ізотропні пологі тонкі оболонки, що нагріваються внутрішніми джерелами тепла, зосередженими у квадраті та еліпсі, на межових поверхнях яких відбувається конвективний теплообмін із навколишнім середовищем. Задачу теплопровідності розв'язано за умов, коли температура навколишнього середовища $є$ сталою, а на безмежності прямує до нуля. Теплові джерела з інтенсивністю, що дорівнює одиниці, розміщено на серединній поверхні, де вибрано початок системи координат. Об'ємну густину джерел нагрівання описано за допомогою двовимірної функції Дірака. Досліджено поведінку температурного поля у однорідних і неоднорідних середовищах та залежність температури від відстані до джерел тепла.

Розроблено інженерну методику дослідження теплових режимів у елементах та вузлах конструкцій радіоелектронної апаратури, яка грунтується на розв'язанні рівняння теплопровідності для прямокутного паралелепіпеда 3 джерелами тепла такої ж геометричної форми. Розроблені модель та алгоритм визначення та аналізу теплових режимів в елементах конструкцій - стійка, блок, мікросхема електронної апаратури дає можливість отримати значення температури для довільної точки структури в аналітичному вигляді. Із розв'язку рівняння теплопровідності отримано співвідношення для визначення ефективної теплопровідності елементів конструкції вздовж основних координатних осей із врахуванням максимально заданого їх перегрівання [1].

У працях $[4,5,6]$ удосконалено наявні та розроблено нові підходи до створення математичних моделей аналізу теплообміну між кусково-однорідними конструкціями та навколишнім середовищем і методів розв'язування лінійних і нелінійних крайових задач для кусково-однорідних середовищ. Розглянуто дво- та тривимірні моделі, що містять рівняння, коефіцієнти яких є фун- 
кціями теплофізичних властивостей фаз і геометричної структури. Наведено методи визначення аналітичних і аналітично-числових розв'язків крайових задач теплопровідності. Досліджено та проаналізовано теплообмінні процеси в однорідних і шаруватих конструкціях із чужорідними включеннями канонічної форми.

У роботах $[16,20]$ наведено загальні рівняння теплопровідності для неоднорідних середовищ.

Огляд основних літературних джерел показав, що малодослідженими та не розробленими залишилися моделі, які б враховували інтенсивні температурні збурення у конструкціях, зумовлені локально зосередженими джерелами тепла. Це приводить до розроблення математичних моделей аналізу теплообмінних процесів у елементах складних електронних і електромеханічних систем, які функціонують у подібних температурних режимах. Результати досліджень теплообміну в таких конструкціях використовують надалі для проектування наведених систем щодо їх термостійкості.

\section{Результати дослідження та їх обговорення / Research results and their discussion}

Об'єкт дослідження та його математична модель. Розглянемо ізотропну шарувату пластину товщиною $2 \delta$ та шириною $2 l 3$ теплоізольованими лицевими поверхнями $|z|=\delta,|x|=l$ та рівномірно розподіленими внутрішніми джерелами тепла 3 потужністю $q_{0}$, яка складається із $n$ шарів. Наведену конструкцію віднесено до системи координат $(x, y, z)$, на поверхнях

$$
K_{0}=\{(x, 0, z):|x| \leq l,|z| \leq \delta\}, K_{n}=\left\{\left(x, y_{n}, z\right):|x| \leq l,|z| \leq \delta\right\}
$$

якої задано стале значення температури $t_{0}$. На поверхнях шарів $K_{i}=\left\{\left(x, y_{i}, z\right):|x| \leq l,|z| \leq \delta\right\}(i=\overline{1, n-1})$ існує ідеальний тепловий контакт $t_{i}=t_{i+1}, \lambda_{i}(t) \frac{d t_{i}}{d y}=\lambda_{i+1}(t) \frac{d t_{i+1}}{d y}$ (рис. 2). У наведеній структурі потрібно визначити розподіл температури $t(y)$ за просторовою координатою $y$, який отримаємо, розв'язавши нелінійне звичайне диференціальне рівняння теплопровідності з розривними коефіцієнтами $[16,20]$

$$
\frac{d}{d y}\left[\lambda(y, t) \frac{d t}{d y}\right]=-q_{0}
$$

і $з$ крайовою умовою $t(0)=t\left(y_{n}\right)=t_{0}$,

де $\quad \lambda(y, t)=\lambda_{1}(t)+\sum_{i=1}^{n-1}\left[\lambda_{i+1}(t)-\lambda_{i}(t)\right] S_{+}\left(y-y_{i}\right)$

- коефіцієнт теплопровідності термочутливої шаруватої пластини. Введемо лінеаризуючу функцію

$$
\vartheta(y)=\int_{0}^{t(y)} \lambda_{1}(\zeta) d \zeta+\sum_{i=1}^{n-1} S_{+}\left(y-y_{i}\right) \int_{t\left(y_{i}\right)}^{t(y)}\left[\lambda_{i+1}(\zeta)-\lambda_{i}(\zeta)\right] d \zeta
$$

і продиференціюємо її за змінною $y$, внаслідок чого отримаємо

$$
\lambda(y, t) \frac{d t}{d y}=\frac{d \vartheta}{d y} .
$$

Із урахуванням співвідношення (5) вихідне нелінійне звичайне диференціальне рівняння теплопровідності з розривним коефіцієнтом (1) зведемо до неоднорідного звичайного диференціального рівняння другого порядку зі сталим коефіцієнтом відносно функції $\vartheta(y)$

$$
\frac{d^{2} \vartheta}{d y^{2}}=-q_{0}
$$

загальний розв'язок якого визначимо у такому вигляді

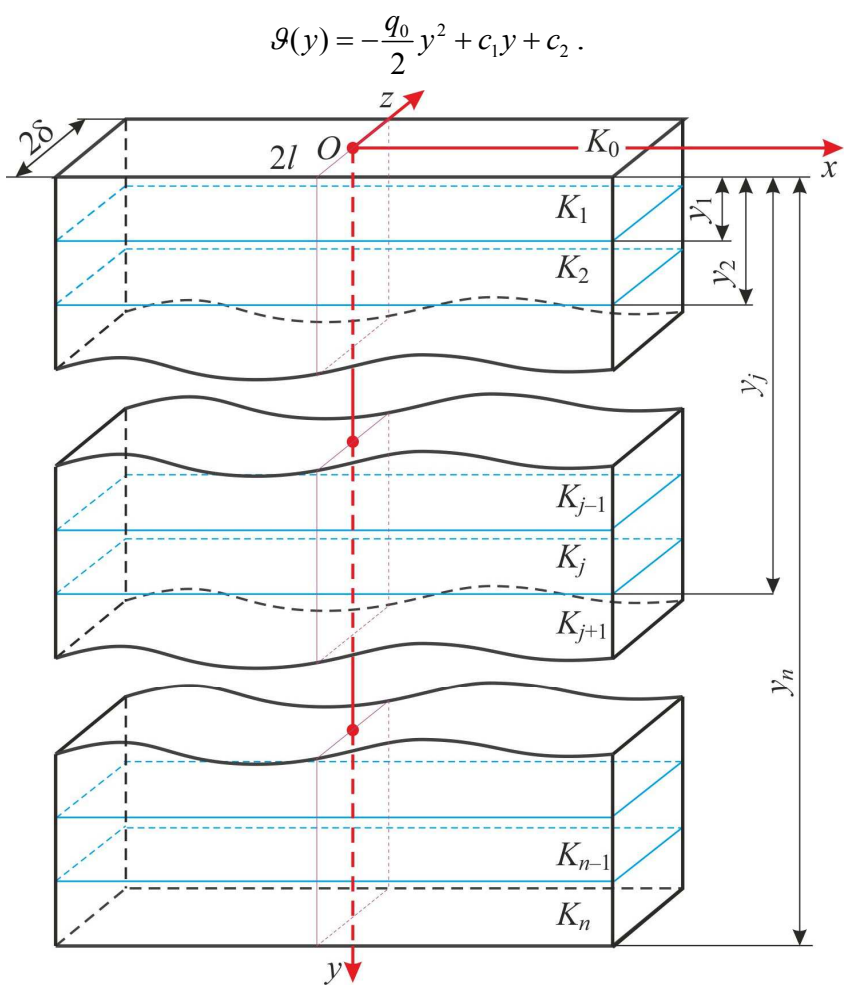

Рис. 2. Ізотропна термочутлива багатошарова пластина під дією внутрішніх джерел тепла / Isotropic heat-sensitive multilayer plate under the action of internal heat sources

Скористаємось крайовими умовами (2), для визначення сталих інтегрування $c_{1}, c_{2}$, які 3 урахуванням співвідношення (4) перетворимо до такого вигляду:

$$
\left.\vartheta\right|_{y=0}=\int_{0}^{t_{0}} \lambda_{1}(\varsigma) d \varsigma,\left.\vartheta\right|_{y=y_{n}}=\int_{0}^{t_{0}} \lambda_{1}(\varsigma) d \varsigma+\sum_{i=1}^{n-1} \int_{t\left(y_{i}\right)}^{t_{0}} \Lambda_{i}(\varsigma) d \varsigma,
$$

де $\Lambda_{i}(\zeta)=\lambda_{i+1}(\zeta)-\lambda_{i}(\zeta)$.

Внаслідок цього отримаємо розв'язок крайової задачі (6) i (7), а саме

$$
\vartheta(y)=y\left\{\frac{q_{0}}{2}\left(y_{n}-y\right)+\frac{1}{y_{n}} \sum_{i=1}^{n-1} \int_{t\left(y_{i}\right)}^{t_{0}} \Lambda_{i}(\zeta) d \varsigma\right\}+\int_{0}^{t_{0}} \lambda_{1}(\zeta) d \zeta .
$$

Обговорення результатів дослідження. Для розв'язування багатьох практичних задач використовують лінійну залежність коефіцієнта теплопровідності від температури [20]

$$
\lambda=\lambda^{0}(1-k t),
$$

де $\lambda^{0}, k$ - опорний і температурний коефіцієнти теплопровідності матеріалу. Із використанням виразів (4), (8) і (9) отримуємо співвідношення для визначення температури

$$
t(y)=\frac{1-\sqrt{1-2 \frac{k}{\lambda^{0}} \vartheta(y)}}{k},
$$

яким повністю описано температурне поле.

Припустимо, що ізотропна термочутлива пластина $\epsilon$ двошаровою, матеріалами шарів якої $є$ кремній та германій. Для наведених конструкційних матеріалів пластини в інтервалі температур $\left[0{ }^{\circ} \mathrm{C} ; 1127^{\circ} \mathrm{C}\right]$ спостерігаємо такі залежності коефіцієнта теплопровідності від температури [15]:

для кремнію $\lambda(t)=67,9 \frac{\mathrm{W}}{\mathrm{Km}}\left(1-0,0005 \frac{1}{\mathrm{~K}} t\right)$, 
для германію $\lambda(t)=60,3 \frac{\mathrm{W}}{\mathrm{Km}}\left(1-0,0008 \frac{1}{\mathrm{~K}} t\right)$,

що є частковими випадками співвідношення (9). Із урахуванням виразів (4), (8), (10), (11) для визначення розподілу температури $t(y)$ у двошаровій пластині отримаємо квадратні рівняння

- для першого $(x, y, z):|x|<\infty, 0 \leq y \leq y_{1},|z| \leq \delta$

$$
\lambda_{1}^{0} k_{1} t^{2}-2 \lambda_{1}^{0} t+\lambda_{1}^{0} t_{0}\left(2-k_{1} t_{0}\right)+\vartheta(y)=0
$$

- i другого $\quad(x, y, z):|x|<\infty, y_{1}<y \leq y_{2},|z| \leq \delta$

$$
\lambda_{2}^{0} k_{2} t^{2}-2 \lambda_{2}^{0} t+t_{0} \Lambda_{1}^{0}+t\left(y_{1}\right) \Lambda\left(y_{1}\right)+\vartheta(y)=0
$$

шарів пластини та на поверхні їх спряження

$$
\begin{gathered}
K_{1}=\left\{\left(x, y_{1}, z\right):|x|<\infty,|z| \leq \delta\right\} \\
\Lambda^{0}\left(k_{1}, k_{2}\right) t^{2}\left(y_{1}\right)-2 \Lambda^{0} t\left(y_{1}\right)+\vartheta\left(y_{1}\right)+t_{0} \Lambda_{1}^{0}=0,
\end{gathered}
$$$$
\text { де: } \quad \vartheta(y)=y\left\{q_{0}\left(y_{2}-y\right)+\frac{1}{y_{2}}\left[t_{0}\left(\Lambda_{2}^{0}-\Lambda_{1}^{0}\right)-t\left(y_{1}\right) \Lambda\left(y_{1}\right)\right]\right\} \text {; }
$$$$
\vartheta\left(y_{1}\right)=y_{1}\left\{q_{0}\left(y_{2}-y_{1}\right)+\frac{t_{0}}{y_{2}}\left[\Lambda_{2}^{0}-\Lambda_{1}^{0}\right]\right\} ;
$$$$
\Lambda_{1}^{0}=\lambda_{1}^{0}\left(2-k_{1} t_{0}\right) ; \Lambda_{2}^{0}=\lambda_{2}^{0}\left(2-k_{2} t_{0}\right) ; \Lambda_{1}^{0}\left(y_{1}\right)=\lambda_{1}^{0}\left(2-k_{1} t\left(y_{1}\right)\right) ;
$$$$
\Lambda_{2}^{0}\left(y_{1}\right)=\lambda_{2}^{0}\left(2-k_{2} t\left(y_{1}\right)\right) ; \Lambda\left(y_{1}\right)=\Lambda_{2}^{0}\left(y_{1}\right)-\Lambda_{1}^{0}\left(y_{1}\right) ;
$$$$
\Lambda^{0}\left(k_{1}, k_{2}\right)=\lambda_{1}^{0} k_{1}+\frac{y_{1}}{y_{2}}\left(\lambda_{2}^{0} k_{2}-\lambda_{1}^{0} k_{1}\right) ; \Lambda^{0}=\lambda_{1}^{0}+\frac{y_{1}}{y_{2}}\left(\lambda_{2}^{0}-\lambda_{1}^{0}\right) .
$$

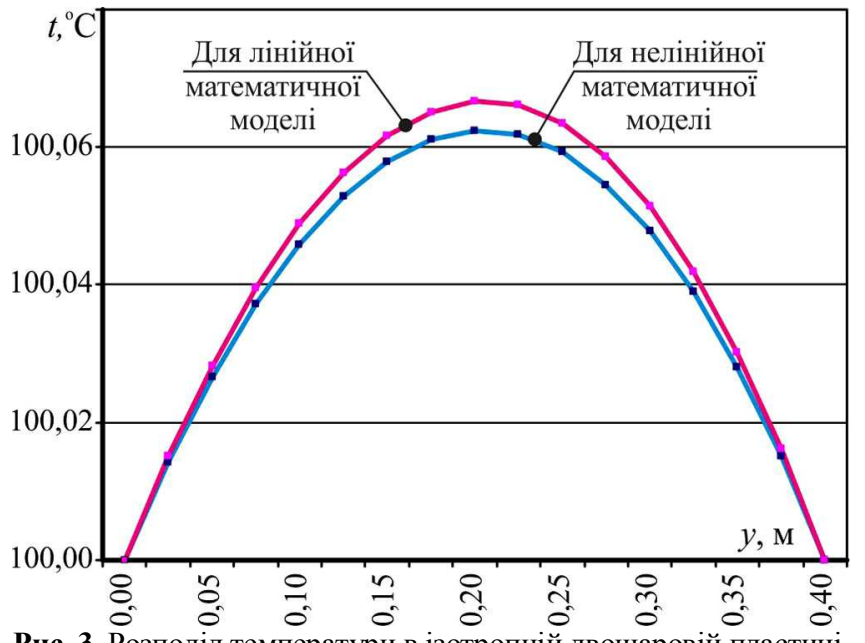

Рис. 3. Розподіл температури в ізотропній двошаровій пластині для лінійної (крива 1) та нелінійної (крива 2) моделей / Temperature distribution in an isotropic two-layer plate for linear (curve 1) and nonlinear (curve 2) models

На рис. 3 зображено поведінку температурного поля у двошаровій пластині, для сталих значень коефіцієнта теплопровідності конструкційних матеріалів пластини $\lambda_{1}=67,9$ вт/(град•м), $\lambda_{2}=60,3$ (вт/(град•м) за температури $27^{\circ} \mathrm{C}$ (крива 1), та лінійно змінного коефіцієнта теплопровідності від температури за співвідношеннями (11) (крива 2). Значення потужності внутрішніх джерел тепла $q_{0}$ і температури $t_{0}$ на межових поверхнях пластини є такими, що дорівнюють $200 \mathrm{вт} / \mathrm{m}^{3}$ та $100{ }^{\circ} \mathrm{C}$ відповідно. Значеннями товщини шарів пластини вибрано $y_{1}=0,2$ м та $y_{2}=0,4$ м. Як видно з рисунка, криві, описані температурою, як функцією просторової координати $y, \epsilon$ неперервними без кутових точок на поверхні спряження шарів, де задано умови ідеального теплового контакту, що свідчить про правильність математичних моделей, як лінійної так і нелінійної, причому аналіз отриманих числових результатів показує, що врахування термочутливості приводить до зменшення значень температури для наведених матеріалів шарів пластини.

\section{Висновки / Conclusions}

Введена лінеаризуюча функція дала змогу лінеаризувати вихідне нелінійне рівняння теплопровідності 3 розривними коефіцієнтами та нелінійні крайові умови. Внаслідок отримано звичайне диференціальне рівняння другого порядку зі сталими коефіцієнтами та лінійні крайові умови для визначення лінеаризуючої функції. Для заданих залежностей коефіцієнта теплопровідності від температури матеріалів шарів пластини визначено аналітичні співвідношення, які повністю описують розподіл температури у шаруватому середовищі внаслідок його внутрішнього нагрівання. Розроблено обчислювальний алгоритм і програмні засоби для визначення температурного поля в довільній точці термочутливої шаруватої пластини 3 внутрішнім тепловим навантаженням. На цій основі отримано числові значення температурного поля, із використанням яких геометрично зображено розподіл температури залежно від просторової координати. Числовий аналіз свідчить, що для наведених матеріалів врахування термочутливості приводить до зменшення значень температури. Наведена нелінійна математична модель дає змогу аналізувати температурні режими у термочутливих шаруватих середовищах, які піддаються внутрішнім тепловим навантаженням щодо їх термостійкості внаслідок інтенсивного нагрівання, а також захистити їх від перегрівання, яке може спричинити руйнування не тільки окремих елементів, а й всієї конструкції.

\section{References}

1. Azarenkov, V. I. (2012). Issledovanie i razrabotka teplovoi modeli i metodov analiza temperaturnikh polei konstruktcii radioelektronnoi apparaturi. Technology audit and production reserves, 3/1(5), 39-40. [In Russian].

2. Carpinteri, A., \& Paggi, M. (2008). Thermoelastic mismatch in nonhomogeneous beams. Journal of Engineering Mathematics, 61(2-4), 371-384. https://doi.org/10.1007/s10665-008-9212-8

3. Dovbnia, K. M., \& Dundar, O. D. (2016). Statsionarnyi teploobmin tonkykh polohykh izotropnykh obolonok, yaki znakhodiatsia pid diieiu dzherel tepla, zoseredzhenykh po dvovymirnii oblasti. Visnyk DonNU. Ser. A: Pryrodnychi nauky, 1-2, 107-112. [In Ukrainian].

4. Havrysh, V. I., \& Fedasjuk, D. V. (2012). Modelling of temperature regimes in piecewise-homogeneous structures. Lviv: Publishing house of Lviv Politechnic National University, $176 \mathrm{p}$.

5. Havrysh, V. I., Baranetskiy, Ya. O., \& Kolyasa, L. I. (2018). Investigation of temperature modes in thermosensitive non-uniform elements of radioelectronic devices. Radio electronics, computer science, management, 3(46),7-15. https://doi.org/10.15588/16073274-2018-3-1

6. Havrysh, V. I., Kolyasa, L. I., \& Ukhanska, O. M. (2019). Determination of temperature field in thermally sensitive layered medium with inclusions. Naukovyi Visnyk NHU, 1, 94-100. https://doi.org/10.29202/nvngu/2019-1/5

7. Hrytsiuk, Yu. I., \& Andrushchakevych, O. T. (2018). Means for determining software quality by metric analysis methods. Scientific Bulletin of UNFU, 28(6), 159-171. https://doi.org/10.15421/40280631

8. Hrytsiuk, Yu. I., \& Buchkovska, A. Yu. (2017). Visualization of the Results of Expert Evaluation of Software Quality Using Polar Diagrams. Scientific Bulletin of UNFU, 27(10), 137-145. https://doi.org/10.15421/40271025

9. Hrytsiuk, Yu. I., \& Dalyavskyy, V. S. (2018). Using Petal Diagram for Visualizing the Results of Expert Evaluation of Software 
Quality. Scientific Bulletin of UNFU, 28(9), 97-106. https://doi.org/10.15421/411832

10. Hrytsiuk, Yu. I., \& Nemova, E. A. (2018). Management Features Process of Developing Software Requirements. Scientific Bulletin of UNFU, 28(8), 161-169. https://doi.org/10.15421/40280832

11. Hrytsiuk, Yu. I., \& Nemova, E. A. (2018). Peculiarities of Formulation of Requirements to the Software. Scientific Bulletin of UNFU, 28(7), 135-148. https://doi.org/10.15421/40280727

12. Hrytsiuk, Yu. I., \& Vovryn, K. Ya. (2018). Software for construction of complex geometric surfaces with spline functions. Scientific Bulletin of UNFU, 28(5), 147-156. https://doi.org/10.15421/40280530

13. Hrytsiuk, Yu. I., \& Zhabych, M. R. (2018). Risk Management of Implementation of Program Projects. Scientific Bulletin of UNFU, 28(1), 150-162. https://doi.org/10.15421/40280130

14. Hrytsiuk, Yu., \& Yatsyshyn, S. (2018). Modeling the forming surfaces of wood trunks using spline functions. Proceedings of the Forestry Academy of Sciences of Ukraine, 18, 165-177. https://doi.org/10.15421/411806

15. Kikoina, I. K. (1976). Tablitcy fizicheskikh velichin. Spravochnik. Moscow: Atomizdat, 1008 p. [In Russian].

16. Koliano, Iu. M. (1992). Metody teploprovodnosti i termouprugosti neodnorodnogo tela. Kyiv: Naukova dumka, 280 p. https://doi.org/10.1192/bjp.161.2.280b

17. Korn, G., \& Korn, T. (1977). Spravochnik po matematike dlia nauchnykh rabotnikov i inzhenerov. Moscow: Nauka, 720 p. [In Russian].
18. Noda, N. (1991). Thermal stresses in materials with temperaturedependent properties. Applied Mechanics Reviews, 44, 383-397. https://doi.org/10.1115/1.3119511

19. Otao, Y., Tanigawa, O., \& Ishimaru, O. (2000). Optimization of material composition of functionality graded plate for thermal stress relaxation using a genetic algorithm. Journal of Thermal Stresses, 23, 257-271. https://doi.org/10.1080/014957300280434

20. Podstrigach, Ia. S., Lomakin, V. A., \& Koliano, Iu. M. (1984). Termouprugost tel neodnorodnoi struktury. Moscow: Nauka, 368 p. [In Russian].

21. Tanigawa, Y., \& Otao, Y. (2002). Transient thermoelastic analysis of functionally graded plate with temperature-dependent material properties taking into account the thermal radiation. $\mathrm{Ni}$ hon Kikai Gakkai Nenji Taikai Koen Ronbunshu, 2, 133-134. https://doi.org/10.1299/jsmemecjo.2002.2.0 133

22. Tanigawa, Y., Akai, T., \& Kawamura, R. (1996). Transient heat conduction and thermal stress problems of a nonhomogeneous plate with temperature-dependent material properties. Journal of $\begin{array}{lll}\text { Thermal } & \text { Stresses, } & \text { 19(1), }\end{array}$ https://doi.org/10.1080/01495739608946161

23. Yangian, $\mathrm{Xu}, \&$ Daihui, Tu. (2009). Analysis of steady thermal stress in a $\mathrm{ZrO} 2 / \mathrm{FGM} / \mathrm{Ti}-6 \mathrm{Al}-4 \mathrm{~V}$ composite ECBF plate with temperature-dependent material properties by NFEM. 2009-WASE Int. Conf. on Informa. Eng, Vol. 2, 433-436. https://doi.org/10.1109/ICICTA.2009.842

V. I. Havrysh, Yu. I. Hrytsiuk

Lviv Polytechnic National University, Lviv, Ukraine

\section{ANALYSIS OF TEMPERATURE REGIMES IN HEAT-SENSITIVE LAYERED ELEMENTS OF DIGITAL DEVICES CAUSED BY INTERNAL HEATING}

A nonlinear mathematical model for determining the temperature field, and later for the analysis of temperature regimes in a thermosensitive isotropic multilayer plate subjected to an internal thermal load, has been developed. For this purpose, the thermal conductivity coefficient for a layered system is described by a single whole using asymmetric unit functions, which makes it possible to consider the boundary thermal conductivity problem with one inhomogeneous nonlinear ordinary differential equation of thermal conductivity with discontinuous coefficients and nonlinear boundary conditions on boundary surfaces. A linearizing function is introduced, by means of which the initial nonlinear equation of thermal conductivity and nonlinear boundary conditions are linearized and as a result an inhomogeneous ordinary differential equation of the second order with constant coefficients with respect to the linearizing function with linear boundary conditions is obtained. To solve the obtained boundary value problem, the method of variation of constants is used and an analytical solution is obtained, which determines the introduced linearizing function. A two-layer heat-sensitive plate is considered and, as an example, a linear dependence of the thermal conductivity on temperature is chosen, which is often used in many practical problems. As a result, analytical relations in the form of quadratic equations are obtained to determine the temperature distribution in the plate layers and on their conjugation surface. Numerical values of temperature with certain accuracy for the set values of thickness of a plate and its layers, spatial coordinates, specific power of internal heat sources, reference and temperature coefficients of thermal conductivity of structural materials of a plate are received. The material of the plate layers are silicon and germanium. To determine the numerical values of temperature in the structure, as well as the analysis of heat transfer processes in the middle of the layered plate due to internal heat loads, software has been developed using a geometric representation of temperature distribution depending on spatial coordinates. The obtained numerical values of temperature testify to the correspondence of the developed mathematical model of the analysis of heat exchange processes in the thermosensitive layered plate with internal heating to the real physical process. The software also makes it possible to analyze this type of environment, which is subjected to internal heat loads, in terms of their heat resistance. As a result, it becomes possible to increase it and protect it from overheating, which can cause the destruction not only of individual elements, but also of the entire structure.

Keywords: temperature field; isotropic thermosensitive plate; thermal conductivity; heat-insulated surface; perfect thermal contact; internal heating. 